\title{
Working Arrangements of Fifteen Child Psychiatrists in a Child Guidance Setting
}

Michael Black, Consultant Psychiatrist and Medical Director, Bedford Child and Family Psychiatric Service and Dora BLACK, Consultant Child Psychiatrist, Edgware General Hospital and Honorary Consultant, Hospital for Sick Children

A group of child and adolescent psychiatrists working in or near London has been meeting regularly for a number of years. There are places for about 20 , and the composition of the group changes as old members leave and are replaced by new ones. In 1974 a pilot study was published on how members divided up their professional time.' Seven years later the present group decided to examine this topic again, ${ }^{2}$ and also to explore other issues concerning their working arrangements.

In the seven years between our studies there have been major reorganizations of the NHS and the Social Services, as well as changes in the organizational structure of child guidance clinics brought about by the DES/DHSS circular on child guidance. ${ }^{3}$ The position of the psychiatrist has changed during this time and in some clinics the consultant is no longer regarded as Medical Director.

\section{The study}

In July 1980 each member was asked to fill in a questionnaire about aspects of their work in different settings. Eighteen replies were received from 23 consultants, 15 of whom worked in 'child guidance' settings. (Although a number of child guidance settings now have a different name, e.g. 'Child and Family Psychiatric Clinic', for the purposes of this paper the term 'child guidance' is used.) Only information relating to 'child guidance' settings is reported on here. We asked for information on clinic staffing, clinic procedure, on-call arrangements, access to beds, leadership issues, and current difficulties.

\section{Clinic staffing}

Medical: Twelve consultants had a hospital appointment or appointments in addition to their clinic work, and eight worked in more than two different types of settings. These additional settings were mainly educational or social service department establishments. In six clinics there were additional sessions provided by other consultants. Only six clinics had sessions for either trainees or other medical staff and only one of these had a full-time senior registrar.

Other: All 15 clinics had social worker sessions and 13 had psychotherapy sessions. Eleven clinics had educational psychologists, but it was not always clear which sessions were part of the school psychological service and which of child guidance. There was also a small number of other different professionals working in a few clinics.

\section{Clinic procedure}

We set out to ascertain who had clinical responsibility for patients referred to and treated in the clinic.

Referrals were commonly allocated at a team meeting. Only one consultant reported that he saw virtually all children and families referred personally to him, and it was the usual practice for some referrals to be taken by team members other than the psychiatrist. It was usually acceptable to non-medical colleagues to deal with a new case if the consultant requested this, although seven consultants considered that they had a right of veto on the treatment plan proposed by other staff members. Most consultants said that their decision to see a referral personally would be accepted by other staff; four, however, would not always agree to see a new case if other staff requested this.

We asked whether consultants thought their employers regarded them as having overall responsibility for children and families referred to them, even if they did not see such referrals personally, and eight believed that this was the case. The other seven said they did not know.

Nearly all clinics used team meetings to resolve important differences over clinical and administrative matters. On the whole this arrangement seemed to work. Another clinic team, although using 'case discussion and consensus' in order to resolve issues concerning patients, appeared to look to the consultant as final arbiter in other matters. However, this was not always successful as one respondent found the lack of any clear mechanism for resolving differences very unsatisfactory.

\section{On-call arrangements}

Traditionally child guidance services have been outpatient services only and there is no clear contractual obligation by the consultant to offer 24-hour cover for emergencies. Nor, indeed, have there been either the consultant or junior medical staff to do so, and non-medical staff have no tradition of offering 24-hour cover.

Ten consultants were clear that they did not offer on-call arrangements in the evenings and at weekends. The remainder did so, although two only in selected cases. On the other hand, virtually all consultants were willing to be contacted out-of-hours in an emergency and arranged cover from other consultant colleagues during absence.

\section{Access to beds}

Although 12 of the consultants also had a hospital appointment, only one had beds. The rest were dependent on other consultants' units, e.g. paediatric, residential adolescent units or adult psychiatric units. Only seven were completely satisfied with this. 


\section{Leadership issues}

Following the 1974 NHS reorganization, the title of Medical Director was abolished in many child guidance clinics. Until that time the consultant psychiatrist was explicitly the leader of the team, but now the position is far from clear. ${ }^{4,5,6}$ We were interested to ascertain who, if anyone, was seen as the leader of each child guidance team and what our members thought about leadership issues.

We asked first whether teams should have leaders and all the consultants were clear that leadership was necessary. There was also considerable agreement that child psychiatrists saw themselves as leader of the team. When consultants were asked who decided who the leader should be, however, there were some variable responses. For example, several respondents considered that leadership was a contractual obligation or implicit in having been appointed Medical Director. In some clinics it was team recognition which supported the consultant's leadership role, although in others the issue was unresolved, and in one it was decided by vote.

Our next question asked what were the rights, responsibilities and constraints on leadership and again there was no unified response. It was generally felt that the leader had a final say over clinical decisions and that this might include the right of veto. The leader was also seen as someone who acted as a facilitator and was spokesman in relation to other agencies. Finally, consultants were asked if the system of leadership enabled them to function effectively as consultant child psychiatrists. In all, 12 who worked in child guidance settings replied 'yes', but their apparent satisfaction was sometimes qualified in other comments.

\section{Current difficulties}

We asked the consultants to comment on difficulties hampering their delivery of a clinical service to the community, and one major problem was lack of sufficient funding. There were several references to lack of enough consultant sessions, but inadequate provision of junior psychiatric staff and other team members was also seen as a problem. These comments are not surprising because it is likely that a number of our members are working in clinics which have less than the levels of staffing recommended either by Underwood in 1955' or by the Royal College of Psychiatrists in $1973^{8}$. It was also pointed out that the present system whereby different disciplines within the clinic were funded by and responsible to different services was divisive. Dealings with other agencies were sometimes difficult-the education authority being most frequently mentioned.

\section{Discussion}

At a time of another reorganisation of the NHS we have an opportunity to plan child psychiatric services which are more appropriate for the 1980 s. There have been recent advances and changes in the practice of child psychiatry, but good practice needs an appropriate organizational framework, and this has not yet been developed. ${ }^{6}$ Although in the years since the last NHS reorganization there have been attempts to examine the organization of child guidance 4 and multidisciplinary work in child guidance, ${ }^{s}$ there is still considerable uncertainty about the current practice and future development of child psychiatry within a child guidance setting. Despite the numbers in our survey being small, it is likely that our findings illustrate difficulties facing other child psychiatrists.

The majority of our consultants worked single handed, few had junior psychiatric staff, and only one had beds. Since no non-medical staff offered any regular out-of-hours service this meant that most consultants did not feel able to offer a 24-hour emergency service, although virtually all were willing to be contacted out-of-hours if necessary. This clearly has implications for the management of child and adolescent psychiatric emergencies, most commonly the young parasuicidal patient. ${ }^{10}$ At present some communities are unclear about the service offered by their child guidance clinic and how quickly it can respond, and referrers may have unrealistic expectations which given current funding and staffing cannot be fulfilled.

Child psychiatric services have developed in a fragmented way and there is still a split between hospital and community services, although the Court Report has recommended that this distinction should be dropped." Child guidance clinics may be funded either by health authorities or by Education Departments. The child psychiatrist in the latter may be at a disadvantage compared with health based colleagues. In our view child psychiatrists need to be in the same position as their consultant colleagues in other specialties where the employing authority, the NHS, also funds the service. We believe that this would help to strengthen the position of the child psychiatrist in the multidisciplinary team and reduce some of the tensions surrounding leadership which are commented on by some of our respondents. The traditional position of the child psychiatrist as solo consultant in a multidisciplinary team in child guidance clinics has resulted in professional isolation and relative impotence in securing the resources necessary for an adequate service to their patients.

We consider that at this time of NHS reorganization child psychiatrists should press for more clearly defined health services for child and adolescent mental health. It is probable that child psychiatric services are grossly under funded. For example, in a recent study it was found that in one Area Health Authority the proportion of funds available to child psychiatry was 1.85 per cent of the Area Health Authority's expenditure for the adult mentally ill and 0.2 per cent of the total health expenditure (Black and Harris, 1982: personal communication). This highlights the need of child psychiatrists to become familiar with planning mechanisms in the new health districts and to join the appropriate committees. We think it essential that every child psychiatrist has 
at least one session in the appropriate district hospital. ${ }^{12}$ Three of the consultants in this study had none.

Although in the past many child guidance clinics have been included in NHS planning groups for community services, it is now necessary to question this, and to consider whether child mental health interests will not be better served by child psychiatric units both in the hospital and in the community joining together with adult psychiatric departments in the same unit of management.

\section{REFERENCES}

'Black, D., Black, M., \& MARTIN, F. (1974) A pilot study on the use of consultant time in child psychiatry. British Journal of Psychiatry Supplement, News and Notes, September, pp 3-5.

${ }^{2}$ BLACK, D. \& BLACK, M. (1982) The use of consultant time in child psychiatry - seven years on. Bulletin of the Royal College of Psychiatrists, 6, 116-7.

${ }^{3}$ DES/DHSS (1974) Child Guidance Circular 3/74 (Department of Education and Science); HSC (1S) 9 (Department of Health and Social Security): WHSC (IS) 5 (Welsh Office).

‘Rowbotrom, R. \& Bromley, G. (1976) Future Organisation in
Child Guidance and Allied Work. Institution of Organisation and Social Studies, Brunel University, Uxbridge. Middlesex.

sChild Guidance Trust (1982) Multidisciplinary Work in Child Guidance.

'Royal College of Psychiatrists (1978) The role, responsibilities and work of the child and adolescent psychiatrist. Bulletin of the Royal College of Psychiatrists, July, pp 127-31.

'Ministry of Education (1955) Report of the Committee on Maladjusted Children. London: HMSO.

${ }^{8}$ Royal College of Psychiatrists (1973) 'Norms' for medical staffing of psychiatric services; (3) Child psychiatry. British Journal of Psychiatry Supplement, News and Notes, December, $\mathrm{pp}$ 4-8.

'GrahaM, P. (1976) Management in child psychiatry: Recent trends. British Journal of Psychiatry, 129, 97-108.

${ }^{10}$ Royal College of Psychiatrists (1982). The management of parasuicide in young people under sixteen. Bulletin of the Royal College of Psychiatrists, 6, 182-5.

"Report of the Committee on Child Health Services (1976) Fit for the Future. London: HMSO.

${ }^{12}$ DHSS (1978) Health Services Development: Court Report on Child Health Services: HC (78) 5 LAC (78) 2.

\section{News Items}

\section{Professor K. Rawnsley}

We offer our congratulations to the College President, Professor Kenneth Rawnsley, Welsh National School of Medicine, who was awarded the CBE in the New Year Honours list.

\section{Clarifying a Legal Point}

At a recent Public Policy Meeting the question of a doctor being subpoenaed to Court for his clinical files was discussed, and Dr Harry Hunter (Balderton Hospital, Newark, Notts) writes to clarify this point. It is hoped that it will be of some interest and help to members. (The example given is taken from Criminal Law Review and concerns the case R. v Westacott, August 1983). It indicates the proper method to be adopted by both defence and prosecution lawyers and doctors.

The Defendant was charged with rape. A witness summons duces tecum had been served on the complainant's general practitioner requiring his attendance at the trial and requiring him 'to produce medical records in your possession relating to the complainant'. This summons was drafted by the Crown Court in response to a letter from the Defendant's solicitors.

In compliance with the summons, the general practitioner brought the records to court, but he handed them to the Defendant's solicitor. The trial judge refused an application by defending counsel to be allowed to cross-examine the complainant on her medical history on the ground that on the facts of the case such cross-examination was not relevant and did not fall within the principle of Toohey $\mathbf{v}$ Metropolitan Police Commissioner (1965) A-C 595. In the event, therefore, the general practitioner did not give evidence and the records themselves were not produced in evidence.

After the jury had retired, the judge indicated to both the defending and prosecuting counsel that it would only be in exceptional cases that a summons duces tecum would be issued for a witness to produce medical records relating to a complainant; and only when it was shown that there were substantial grounds for believing that such records contained relevant matters.

Where such a summons was issued, it should be made absolutely clear to the witness that he was only to produce the documents to the Court and not to disclose them to the legal advisers of the Prosecution or the Defence until the Court had decided whether they should be disclosed.

\section{Audio-Cassettes on the Mental Health Act 1983}

Professor Norman Tutt and Dr Henri Giller have produced, in conjunction with Professor Rolf Olsen, a set of C60 audio-cassettes on the new Act. The tapes provide: (i) a review of the issues which led to the campaign for legislative reform; (ii) a summary and interpretation of the Act; (iii) a discussion of the major provisions of the Act; and (iv) the duties and obligations placed upon the Approved Social Worker and Local Authority Social Services Departments.

The cost of the tapes is $£ 15$ per set and they are available from: Information Systems (Lancaster), Caton House, High Casterton, Kirkby Lonsdale, Cumbria. 